\title{
An examination of word relevance in a modified Stroop task in patients with chronic low back pain.
}

Citation for published version (APA):

Roelofs, J., Crombez, G., Peters, M. L., Vlaeyen, J. W. S., \& Verschuere, B. (2005). An examination of word relevance in a modified Stroop task in patients with chronic low back pain. Perceptual and Motor Skills, 100, 955-963. https://doi.org/10.2466/pms.100.3c.955-963

Document status and date:

Published: 01/01/2005

DOI:

10.2466/pms.100.3c.955-963

Document Version:

Publisher's PDF, also known as Version of record

Document license:

Taverne

Please check the document version of this publication:

- A submitted manuscript is the version of the article upon submission and before peer-review. There can be important differences between the submitted version and the official published version of record.

People interested in the research are advised to contact the author for the final version of the publication, or visit the DOI to the publisher's website.

- The final author version and the galley proof are versions of the publication after peer review.

- The final published version features the final layout of the paper including the volume, issue and page numbers.

Link to publication

\footnotetext{
General rights rights.

- You may freely distribute the URL identifying the publication in the public portal. please follow below link for the End User Agreement:

www.umlib.nl/taverne-license

Take down policy

If you believe that this document breaches copyright please contact us at:

repository@maastrichtuniversity.nl

providing details and we will investigate your claim.
}

Copyright and moral rights for the publications made accessible in the public portal are retained by the authors and/or other copyright owners and it is a condition of accessing publications that users recognise and abide by the legal requirements associated with these

- Users may download and print one copy of any publication from the public portal for the purpose of private study or research.

- You may not further distribute the material or use it for any profit-making activity or commercial gain

If the publication is distributed under the terms of Article $25 \mathrm{fa}$ of the Dutch Copyright Act, indicated by the "Taverne" license above, 


\title{
AN EXAMINATION OF WORD RELEVANCE IN A MODIFIED STROOP TASK IN PATIENTS WITH CHRONIC LOW BACK PAIN ${ }^{1,2}$
}

\author{
JEFFREY ROELOFS \\ Maastricht University \\ MADELON L. PETERS \\ Maastricht University
}

GEERT CROMBEZ

Ghent University

BRUNO VERSCHUERE

Ghent University

\author{
JOHAN W. S. VLAEYEN \\ Maastricht University
}

\begin{abstract}
Summary.-The present study examined the role of personal relevance of sensory pain-related words in selective attentional processing measured with a modified Stroop task administered to 30 patients with chronic low back pain. A related aim of this study was to introduce the application of multilevel analysis to test the influence of personal relevance on selective attentional processing in this sample. Patients completed the modified Stroop task, as well as a set of self-report measures aimed to assess Fear of Pain, Trait Anxiety, Catastrophizing, Pain Vigilance, and Pain Intensity. The modified Stroop task comprised 33 sensory pain-related words for which the personal relevance towards current concerns was rated afterwards by each participant on a 7 -point Likert-type scale. The multilevel analyses did not support the hypothesis that personal relevance of sensory pain-related words interacted with Fear of Pain scores of patients in accounting for reaction times in naming the color of sensory pain-related words. None of the other self-report measures accounted for reaction times in isolation or in interaction with personal relevance. The modified Stroop task does not appear to be a robust measure of selective attentional processing in patients with chronic low back pain. The usefulness of other paradigms, such as the visual dotprobe task, should be explored in examining selective attentional processing in this population.
\end{abstract}

Research into biases in information processing has predominantly involved the area of emotional disorders such as depression, eating disorders, and several anxiety disorders. This research, inspired by Beck's schema theory (Beck, 1976; Beck, Emery, \& Greenberg, 1986) and Bower's network theory of the relation between emotion and cognition (Bower, 1981, 1987), has uncovered biases in memory, interpretation, and attention. Recently, investigation of information-processing biases has also been applied to the field of chronic pain. In an extensive review, Pincus and Morley (2001) concluded that there is strong evidence for the presence of memory bias and

\footnotetext{
${ }^{1}$ We thank Murielle Verschuere for the assistance in collecting data in the present study. ${ }^{2}$ Address correspondence to Jeffrey Roelofs, Ph.D., Department of Medical, Clinical and Experimental Psychology, Maastricht University, P.O. Box 616, 6200 MD Maastricht, The Netherlands or e-mail (J.Roelofs@dep.unimaas.nl).
} 
interpretation bias towards pain-related stimuli in pain patients. There was only limited evidence for selective attention towards pain-related stimuli in chronic pain patients. However, a recent meta-analysis (Roelofs, Peters, Zeegers, \& Vlaeyen, 2002) indicated that chronic pain patients do selectively pay attention to pain stimuli, i.e., sensory and affective pain words, as measured with a modified Stroop task.

In a modified Stroop task, categories of emotionally salient and neutral words are presented in different colors. Response times of patients to name the color of each word are measured. Typically, color naming is slowed down when words are relevant to the patients' concerns, whereas no response delay is expected for neutral words. Although the overall conclusion of the meta-analysis on Stroop studies was that chronic pain patients selectively pay attention to pain-related words, not all studies included in the meta-analysis yielded support for selective attention towards pain-related words. One reason for lack of expected attentional effects may be that words are, for many patients, not relevant to their own pain and therefore do not capture their current concerns. The importance of using words in a modified Stroop task that accurately tap current concerns, referred to as 'personal relevance' in the following text, has been stressed in several studies conducted on different anxiety disorders (see Williams, Watts, MacLeod, \& Mathews, 1997, for an overview). Another reason may be that not all pain patients show a specific interference effect. In line with the view of Eccleston and Crombez (1999) and Vlaeyen and Linton (2000), it is reasonable to hypothesize that especially those patients who are fearful about their pain or who catastrophize about their pain will display increased attention to pain or pain-related information.

To date, only one study has addressed personal relevance of pain words using the modified Stroop task (Andersson \& Haldrup, 2003), in which personalized pain words were chosen before the actual experiment. This study showed slower response times on pain words compared to neutral words for pain patients. The present study offers an alternative approach, namely, multilevel analysis, to examine the extent to which personal relevance of pain words accounts for reaction times of naming the color of sensory pain-related words in patients with chronic low back pain. The present study relied solely on sensory pain-related words since meta-analysis has shown that pain patients show a Stroop effect for sensory pain-related words (Roelofs, et al., 2002). Moreover, the recently proposed 'enmeshment model' by Pincus and Morley (2001) accounts for evidence regarding attentional, interpretation, and memory biases in chronic pain patients, by assuming the pain patients would selectively process information on sensory intensity.

The present study used a modified Stroop task, but it should be noted that we did not examine a conventional Stroop effect for sensory pain-re- 
lated words since a neutral word category was not included. Rather, we examined whether response times of naming the color of sensory pain-related words were related to personal relevance. We predicted that the more personally relevant sensory pain-related words are, the slower the reaction times to name the color of these words would be. Furthermore, we hypothesized that an interaction between Fear of Pain and ratings of personal relevance of sensory pain-related words would be present, such that higher Fear of Pain together with words that are more personally relevant to patients with chronic low back pain, would account for reaction times of naming the color of sensory pain-related words. The specificity of fear of pain in predicting reaction times was investigated by examining whether measures of Trait Anxiety, Catastrophizing, and current Pain Intensity interacted with personal relevance in accounting for reaction times of naming the color of sensory painrelated words. Finally, we examined to what extent these self-report measures and personal relevance in isolation accounted for reaction times on sensory pain-related words.

\section{Method}

\section{Participants}

Thirty patients with chronic low back pain (19 women, 11 men; $M=$ 41.2 yr., $S D=11.6$ ) were recruited from two Belgian pain clinics at the University Hospital of Ghent and the University Hospital of Leuven at 'Pellenberg'. The inclusion criteria for the present experiment were nonspecific complaints about back pain for a duration of at least six months, ages between 18 and 65 years, and mastery of the Dutch language. Written informed consent was obtained for each participant before the start of the experiment.

\section{Materials and Procedure}

Each participant completed a computerized version of the modified Stroop task, which contained 33 Dutch sensory pain-related words derived from the McGill Pain Questionnaire (see Melzack, 1975; Dutch version: Van der Kloot \& Vertommen, 1989). Each word was presented in four different colors, i.e., red, yellow, blue, and green, for a total number of 132 trials. Each word was presented with a maximum duration of $2000 \mathrm{msec}$, and response times for naming the color were recorded by a voice key. Interstimulus time was $3000 \mathrm{msec}$. Incorrect responses, e.g., wrong color, coughing, were coded by the experimenter. As each word appeared four times, a mean reaction time was calculated. Before the calculation of mean reaction times, incorrect responses were excluded. The Stroop task lasted approximately 8 minutes (without practice). Recording of presentation time was controlled by a Turbo Pascal timer. 
At the end of the experiment, all participants were requested to complete a set of questionnaires, which had to be sent back to the experimenter by mail. Personal Relevance of the sensory pain-related words to the pain experience was measured on a 7 -point Likert-type scale with anchors of $1=$ not at all applicable and $7=$ very applicable to my pain.

The Tampa Scale for Kinesiophobia (Miller, Kori, \& Todd, 1991; Dutch version: Vlaeyen, Kole-Snijders, Boeren, \& Van Eek, 1995) is a 17-item selfreport measure of Fear of Pain that consists of two subscales that are labeled Somatic Focus (e.g., "My body is telling me I have something dangerously wrong") and Activity Avoidance (e.g., "I am afraid that I might injure myself if I exercise"). All items are rated on a 4-point Likert-type scale with anchors of $1=$ strongly agree and $4=$ strongly disagree. Reliability and validity of the Dutch version of the Tampa Scale for Kinesiophobia are good (Goubert, Van Damme, Crombez, Vlaeyen, Bijttebier, \& Roelofs, 2004; Roelofs, Peters, Vlaeyen, Goubert, \& Crombez, 2004).

The Trait Anxiety Scale of the State-Trait Anxiety Inventory (Spielberger, Gorsuch, \& Lushene, 1970; Dutch version: Van der Ploeg, Defares, \& Spielberger, 1980) contains 20 items representing Trait Anxiety (e.g., "I feel nervous"). Items are rated on a 4 -point scale with anchors of $1=$ almost never and $4=$ almost always. Reliability and construct validity of the Dutch version of the State-Trait Anxiety Inventory are supported (Van der Ploeg, et al., 1980).

The Pain Catastrophizing Scale (Sullivan, Bishop, \& Pivik, 1995; Dutch version: Van Damme, Crombez, Bijttebier, Goubert, \& Van Houdenhove, 2002) is a 13-item self-report measure of catastrophizing related to pain. The Pain Catastrophizing Scale consists of three subscales that are labeled Rumination (e.g., "I keep thinking about how badly I want the pain to stop"), Magnification (e.g., "I wonder whether something serious may happen"), and Helplessness (e.g., "I feel I can't go on"). All items are rated on a 4point Likert-type scale with anchors of $1=$ not at all and $4=$ all the time. Reliability and validity of the Dutch version of the Pain Catastrophizing Scale are supported (Van Damme, et al., 2002).

The Pain Vigilance and Awareness Questionnaire (McCracken, 1997; Dutch version: Roelofs, Peters, McCracken, \& Vlaeyen, 2003) is a 16-item measure of pain vigilance. The Pain Vigilance and Awareness Questionnaire has two subscales that are labeled Attention to Pain (e.g., "I focus on sensations of pain") and Attention to Changes in Pain (e.g., "I am quick to notice changes in pain intensity"). All items are rated on a 6-point scale with anchors of $0=$ never and $5=$ always. Reliability and validity of the Pain Vigilance and Awareness Questionnaire is supported (Roelofs, et al., 2003).

Current Pain Intensity was measured on a $100-\mathrm{mm}$ visual analogue scale with anchors "No pain" and "The worst imaginable pain." 


\section{Statistical Analyses}

Multilevel analysis was used to analyze the data. Multilevel analysis can be used for repeated measures and nested data (Snijders \& Bosker, 1999). Personal Relevance of sensory pain-related words was rated by each participant. In this respect, participants comprised the highest (first) level while relevance ratings of the 33 sensory pain-related words comprised the second level. These relevance ratings (second level) were thus nested within participants (first level). In contrast to traditional statistical tests such as ordinary least squares regression techniques, multilevel analysis accounts for intraclass correlation in the data, i.e., relevance ratings within patients may be more strongly interrelated, compared to ratings between patients. Multilevel analysis also has the advantage that it deals with occasional missing data. In nine subsequent analyses, the predictors of reaction times of naming the color of sensory pain-related words (dependent variable) were Fear of Pain, Trait Anxiety, Catastrophizing, Pain Vigilance, and Pain Intensity in isolation and in combination with personal relevance ratings of sensory pain-related words. Personal Relevance of words as a predictor of reaction time in isolation was also examined. To decrease the likelihood of spurious findings due to Type I error, only total scores of the self-report measures were taken into analyses, and alpha was set to .01 for the multilevel analysis. Data were analyzed using the mixed model analysis option in SPSS Version 11.0.

\section{RESULTS}

Table 1 presents descriptive statistics of the questionnaire scores and Pearson correlation coefficients between the various measures. Mean pain duration and age are included. As expected, all self-report measures related to pain, i.e., Fear of Pain, Catastrophizing, Pain Vigilance, and Pain Intensity, were moderately intercorrelated. Trait Anxiety was moderately associated with Fear of Pain and Catastrophizing, but not with Pain Vigilance and Pain Intensity. Age was positively associated with Fear of Pain and Trait Anxiety.

TABLE 1

Descriptive Statistics and Correlations

\begin{tabular}{|c|c|c|c|c|c|c|}
\hline \multirow[t]{2}{*}{ Measure } & \multirow[t]{2}{*}{$M$} & \multirow[t]{2}{*}{$S D$} & \multicolumn{4}{|c|}{ Correlation } \\
\hline & & & 1 & 2 & 3 & 4 \\
\hline 1. Fear of Pain & 40.7 & 7.1 & & & & \\
\hline 2. Trait Anxiety & 40.8 & 9.1 & $.65 \dagger$ & & & \\
\hline 3. Catastrophizing & 22.8 & 8.7 & $.63 \dagger$ & $.52 \dagger$ & & \\
\hline 4. Pain Vigilance & 42.6 & 9.6 & $.47 *$ & .30 & $.58 \div$ & \\
\hline Pain Intensity & 48.2 & 24.9 & $.57 \dagger$ & .12 & $.47 *$ & $.52 *$ \\
\hline Pain Duration & 75.6 & 86.9 & .35 & .14 & .07 & .19 \\
\hline Age, yr. & 41.2 & 11.6 & $.45 *$ & $.40 *$ & .15 & .08 \\
\hline
\end{tabular}

${ }_{p} p<.05 .+p<.01$. 
Two remarks need to be further addressed. First, two patients did not return the questionnaires to the experimenter, and three patients only completed part of the questionnaires. Thus, the sample size in the analyses varied from 25 to 30 depending on the available data. Second, women scored significantly higher on measures of Fear of Pain $(p=.008)$, Trait Anxiety ( $p$ $=.02$ ), and Catastrophizing $(p=.05)$. Word relevance ratings showed sufficient spread $(M=3.1, S D=2.2$; range 1 to 7$)$.

The results of the multilevel analyses are depicted in Table 2. All tested models controlled for sex and age, which did not significantly predict response times (data not shown). As can be seen in Table 2, the expected interaction between Fear of Pain and Personal Relevance ratings of sensory pain words (Model 6) was not confirmed in the present study. Further, none of the other predictors significantly accounted for reaction times to sensory pain words.

TABLE 2

Multilevel Analyses of Reaction Time

\begin{tabular}{|c|c|c|c|c|c|}
\hline Model and Predictor & Beta & SE & $\begin{array}{c}95 \% \text { CI } \\
\text { (Beta) }\end{array}$ & $t$ & $p$ \\
\hline 1: Fear of Pain & 0.26 & 0.21 & $-0.17,0.69$ & 1.26 & .22 \\
\hline 2: Trait Anxiety & 0.18 & 0.19 & $-0.21,0.58$ & 0.95 & .35 \\
\hline 3: Catastrophizing & 0.27 & 0.18 & $-0.10,0.63$ & 1.52 & .14 \\
\hline 4: Pain Intensity & 0.07 & 0.17 & $-0.29,0.43$ & 0.39 & .70 \\
\hline 5: Personal Relevance & -0.02 & 0.02 & $-0.06,0.02$ & -1.02 & .31 \\
\hline 6: Personal Relevance $\times$ Fear of Pain & -0.05 & 0.14 & $-0.32,0.23$ & -0.33 & .75 \\
\hline 7: Personal Relevance $\times$ Trait Anxiety & -0.06 & 0.11 & $-0.27,0.15$ & -0.57 & .57 \\
\hline 8: Personal Relevance $\times$ Catastrophizing & -0.08 & 0.07 & $-0.22,0.06$ & -1.07 & .28 \\
\hline 9: Personal Relevance $\times$ Pain Intensity & -0.09 & 0.06 & $-0.20,0.03$ & -1.44 & .15 \\
\hline
\end{tabular}

Note.-All tested models controlled for sex and age.

\section{Discussion}

The present study examined whether reaction times to name the color of sensory pain-related words could be explained by the personal relevance of these words in isolation and/or in interaction with scores on self-report measures of Fear of Pain, Trait Anxiety, Catastrophizing, and Pain Intensity. The effects of these measures in isolation on reaction times were also investigated. Results showed that the hypothesized interaction between personal relevance ratings and Fear of Pain was not supported in the present study. Further, all self-report measures, personal relevance ratings, and interactions among them, were not predictive of reaction times.

The results from this study do not allow for a direct comparison with the results obtained by Andersson and Haldrup (2003), as we only used sensory pain-related words. The rationale behind the use of sensory pain-related 
words was that some of these pain words are more personally relevant to patients and may subsequently activate the pain schemas to a greater extent than pain words that are not relevant to patients' concerns. However, the present study did not find any effects of personal relevance on response times of naming the color of sensory pain-related words. We cannot answer the question whether response times for naming the color of sensory pain-related words would be delayed as this requires the inclusion of a category of control words. As a consequence, it is unknown whether pain patients preferentially pay attention to sensory pain-related words or may also have retarded reaction times for other word categories. Relying solely on sensory pain-related words may also lead to small effect sizes. The results from the present study are in contrast to studies designed to investigate the role of current concerns in anxiety disorders in applying the modified Stroop task (see Williams, et al., 1997).

Some methodological differences between the present study and studies that have addressed similar research issues in anxiety disorders warrant attention. First, the study design differs from studies examining current concerns in anxiety disorder. In the present study, relevance of words to current concerns was rated afterwards and was taken into account in the multilevel analyses. Studies conducted in the field of anxiety disorders have predominantly relied on a priori independently varying the magnitude of specific relevance to the personal concern of the word stimuli. Second, as only sensory pain words were used, one cannot rule out that other word stimuli such as affective pain words might have tapped current concerns in a more precise way. Third, one could argue that in participants who actually experienced pain currently, the expected effects on reaction times for relevant sensory pain words do not occur. The function of selective attention to a word that may be threatening and related to patients' current concerns is to avoid its possible occurrence. It has been shown that selective attention for threat-related stimuli may disappear in fearful individuals when they are tested in close temporal or physical proximity to their phobic object or situation, such as someone who is snake-phobic tested in the presence of a boa constrictor (Mathews \& Sebastian, 1993), but the opposite results have also been reported (e.g., Chen, Lewin, \& Craske, 1996). Furthermore, pain intensity has predicted Stroop interference effects in pain patients (Crombez, Hermans, \& Adriaensen, 2000).

There are some other limitations of this study in addition to the lack of a neutral word category. First, it may also be that personal relevance of sensory pain-related words is a subtle state-driven variable. State anxiety scores in interaction with personal relevance might have been a good candidate to account for reaction times of sensory pain-related words but was not measured in this study. Second, one may further argue that there was no pain- 
free control group, but it should be noted that a control group was not necessary to address the hypothesis. Taken together, the present study did not yield evidence for the proposition that word relevance in interaction with Fear of Pain scores would predict reaction times as measured with the modified Stroop task in patients with chronic low back pain. Taking the mixed results of previous Stroop studies into account, the best conclusion that can be drawn at this point is that the Stroop task does not seem to be a robust measure for measuring interference effects in patients with chronic low back pain. It is possible that these interference effects are small effects that may not be present in all pain patients. Further studies should apply alternative paradigms, such as the dot-probe task, as a measure of selective attentional processing in patients with chronic low back pain (cf. Asmundson, Kuperos, \& Norton, 1997). It is possible that the word stimuli were not emotionally salient enough to produce selective attentional processing. Therefore, not only words but also pictures should be included, and these stimuli should preferably be chosen idiosyncratically.

\section{REFERENCES}

Andersson, G., \& Haldrup, D. (2003) Personalized pain words and Stroop interference in chronic pain patients. European Journal of Pain, 7, 431-438.

Asmundson, G. J. G., Kuperos, J. L., \& Norton, G. R. (1997) Do patients with chronic pain attend to pain-related information? Preliminary evidence for the mediating role of fear. Pain, 72, 27-32.

BECK, A. T. (1976) Cognitive therapy and the emotional disorders. New York: International Universities Press.

Beck, A. T., Emery, G., \& GreenberG, R. C. (1986) Anxiety disorders and phobias: a cognitive perspective. New York: Basic Books.

Bower, G. H. (1981) Mood and memory. American Psycbologist, 36, 129-148.

Bower, G. H. (1987) Commentary on mood and memory. Bebaviour Research and Therapy, $25,443-456$.

Chen, E., Lewin, M. R., \& Craske, M. G. (1996) Effects of state anxiety on selective attentional processing of threatening information. Cognition \& Emotion, 10, 225-240.

Crombez, G., Hermans, D., \& Adriaensen, H. (2000) The emotional Stroop task and chronic pain: what is threatening for chronic pain sufferers? European Journal of Pain, 4, 37-44.

Eccleston, C., \& Crombez, G. (1999) Pain demands attention: a cognitive-affective model of the interruptive function of pain. Psychological Bulletin, 125, 356-366.

Goubert, L., Van Damme, S., Crombez, G., Vlaeyen, J. W. S., Bijttebier, P., \& Roelofs, J. (2004) Confirmatory factor analysis of the Tampa Scale for Kinesiophobia: invariant two-factor model across low back pain patients and fibromyalgia patients. Clinical Journal of Pain, 20, 103-110.

Mathews, A., \& Sebastian, S. (1993) Suppression of emotional Stroop effects by fear arousal. Cognition \& Emotion, 7, 517-530.

McCracken, L. M. (1997) Attention to pain in persons with chronic pain: a behavioral approach. Behavior Therapy, 28, 271-284.

Melzack, R. (1975) The McGill Pain Questionnaire: major properties and scoring methods. Pain, 1, 277-299.

Miller, R. P., Kori, S., \& Todd, D. D. (1991) The Tampa Scale. (Unpublished report, Tampa, FL)

Pincus, T., \& Morley, S. J. (2001) Cognitive-processing bias in chronic pain: a review and integration. Psychological Bulletin, 127, 599-617. 
Roflofs, J., Peters, M. L., McCracken, L. M., \& Vlaeyen, J. W. S. (2003) The Pain Vigilance and Awareness Questionnaire (PVAQ): further psychometric evaluations in fibromyalgia and other chronic pain syndromes. Pain, 101, 299-306.

Roelofs, J., Peters, M. L., Vlaeyen, J. W. S., Goubert, L., \& Crombez, G. (2004) The Tampa Scale for Kinesiophobia: further examination of psychometric properties in patients with chronic low back pain and fibromyalgia. European Journal of Pain, 8, 495-502.

Roelofs, J., Peters, M. L., Zeegers, M. P. A., \& Vlaeyen, J. W. S. (2002) The modified Stroop paradigm as a measure of selective attention towards pain-related stimuli among chronic pain patients: a meta-analysis. European Journal of Pain, 6, 273-281.

Snijders, T., \& Bosker, R. (1999) Multilevel analysis: an introduction to basic and advanced multilevel modeling. London: Sage.

Spielberger, C. D., Gorsuch, R. L., \& Lushene, R. E. (1970) State-Trait Anxiety Inventory. Palo Alto, CA: Consulting Psychologists Press.

Sullivan, M. J., Bishop, S. R., \& Pivik, J. (1995) The Pain Catastrophizing Scale: development and validation. Psychological Assessment, 7, 624-632.

Van Damme, S., Crombez, G., Bijttebier, P., Goubert, L., \& Van Houdenhove, B. (2002) A confirmatory factor analysis of the Pain Catastrophizing Scale: invariant factor structure across clinical and non-clinical populations. Pain, 96, 319-3:4.

VAN der Kloot, W. A., \& Vertommen, H. (1989) De MPQ- 'LV. Een standaard Nederlandstalige versie van de McGill Pain Questionnaire. Acbte"gronden en bandleiding. Lisse: Swets \& Zeitlinger.

Van der Ploeg, H. M., Defares, P. B., \& Spielberger, C. D. (1980) Handleiding bij de Zelf Beoordelingsuragenlijst (ZBV). Lisse: Swets \& Zeitlinger.

Vlaeyen, J. W. S., Kole-Snijders, A. M. J., Boeren, R. G. B., \& Van Eek, H. (1995) Fear of movement/(re)injury in chronic low back pain and its relation to behavioral performance. Pain, 62, 363-372.

Vlaeyen, J. W. S., \& Linton, S. J. (2000) Fear-avoidance and its consequences in chronic musculoskeletal pain: a state of the art. Pain, 85, 317-3;2.

Williams, J. M. G., Watts, F. N., MacLeod, C., \& Marhews, A. (1997) Cognitive psychology and the emotional disorders. (2nd ed.) Chichester, UK: Wiley.

Accepted May 13, 2005. 